\title{
Experimental study of loop shape using 0.025-inch ERCP guidewires (with videos)
}

\section{다 (i) $\odot$}

\author{
Authors \\ Takeshi Ogura, Saori Ueno, Atsushi Okuda, Nobu Nishioka, Tadahiro Yamada, Masanori Yamada, Kazuya Ueshima, \\ Jun Matsuno, Yoshitaro Yamamoto, Kazuhide Higuchi
}

Institution

2nd Department of Internal Medicine, Osaka Medical

College, Osaka, Japan

submitted 24.6.2020

accepted after revision $\quad 5.10 .2020$

Bibliography

Endoscopy International Open 2021; 09: E427-E437

DOI 10.1055/a-1319-0915

ISSN 2364-3722

(c) 2021. The Author(s).

This is an open access article published by Thieme under the terms of the Creative Commons Attribution-NonDerivative-NonCommercial License, permitting copying and reproduction so long as the original work is given appropriate credit. Contents may not be used for commecial purposes, or adapted, remixed, transformed or built upon. (https://creativecommons.org/licenses/by-nc-nd/4.0/)

Georg Thieme Verlag KG, Rüdigerstraße 14,

70469 Stuttgart, Germany

Corresponding author

Takeshi Ogura, 2nd Department of Internal Medicine, Osaka Medical College, 2-7 Daigakuchou, Takatsukishi, Osaka 5698686, Japan

Fax: $+81-726846532$

oguratakeshi0411@yahoo.co.jp

\section{ABSTRACT}

Background and study aims Duct penetration by the guidewire sometimes occurs during endoscopic retrograde cholangiography, which might lead to adverse events such as acute pancreatitis. To prevent duct penetration, making a loop shape with the guidewire might provide a useful technique. The aim of this experimental study was thus to evaluate which types of guidewire can most easily form a loop shape.

Methods This experimental study evaluated six guidewires (0.025-inch, angle type): MICHISUJI; VisiGlide 2; Jagwire; Pathcorse; RevoWave- $\alpha$ UltraHard 2; and M-through. Flexibility of the tip, shaft stiffness, and the ability to form a loop were evaluated for each type in an ex vivo model. Deformation behavior was also recorded on video, and factors suitable for making a loop shape in each guidewire were evaluated.

Results Flexibility and stiffness of each guidewire differed significantly. During an experimental study regrading deformation behavior before forming a loop shape, maximum load was lower for MICHISUJI $(6.8 \mathrm{~g})$ than for other guidewires (Jagwire [11.3g], M-through [12.9g], VisiGlide 2 [12.9g], Revowave [21 g], and Pathcorse [25.4g]). Mean time required to achieve a loop shape was as follows: MICHISUJI, 6.2 seconds; M-through, 8.7 seconds; VisiGlide 2, 11.0 seconds; and Revowave, 7.1 seconds.

Conclusion In conclusion, characteristics of flexibility and stiffness among guidewires were significantly different in the ex-vivo study. In the experimental study regrading deformation behavior until achieving a loop shape, maximum load also differed. To evaluate whether guidewires easily form a loop shape, clinical study is needed.

\section{Introduction}

To date, various biliary cannulation techniques have been described, such use of a double guidewire or physician-controlled guidewire technique, and techniques for metal stent deployment to treat malignant hilar biliary obstruction, such as stent-in-stent, side-by-side, or hybrid stent deployment techniques in endoscopic retrograde cholangiopancreatography
(ERCP) procedures [1-6]. Recently, interventional endoscopic ultrasound (EUS), such as hepaticogastrostomy, choledochoduodenostomy, or pancreatic transluminal drainage, has also been developed $[7,8]$. As a common point of importance, a guidewire plays a crucial role in procedures. Furthermore, because various kinds of guidewires are available in Japan, selection of a guidewire is also important. Most endoscopists might select a 0.025 - or 0.035 -inch guidewire. Compared with a 
0.035 -inch guidewire, the 0.025 -inch version is obviously thinner, and procedures such as the two-devices-in-one-channel method might thus be performed more easily. On the other hand, duct penetration by a guidewire sometimes occurs during ERCP, and might lead to adverse events (AEs) such as acute pancreatitis. To prevent duct penetration, guidewire flexibility might be important. Forming a loop shape with the guidewire might be a useful technique to prevent duct penetration [9].

On the other hand, several authors have described the clinical benefits of using a loop-tip guidewire during biliary cannulation $[10,11]$. Compared with conventional guidewires, the risk of insertion into a pancreatic branch duct is lower with a loop-tip guidewire due to its shape. Loop shape might thus prevent pancreatic or bile duct injury. However, loop-tip guidewires are not yet available in Japan, but procedures such as selective advancement to the objective duct or through the stricture site might be difficult after biliary cannulation. Conventional guidewires are thus commonly selected as ERCP guidewires.

The ability to create a loop shape differs among types of guidewires. Experimental studies of loop shape have been reported in endourology and the endovascular field [12-15], but not in the pancreatic and biliary endoscopic fields [15]. In addition, from the perspective of loop shape, no evidence has been accumulated regarding which guidewires most easily take on a loop shape. The aim of this experimental study was to evaluate which types of guidewires can most easily from a loop shape.

\section{Materials and methods}

This experimental study evaluated six guidewires (0.025-inch, angle type): MICHISUJI (KANEKA Medical, Osaka, Japan); VisiGlide 2 (Olympus Medical Systems, Tokyo, Japan); Jagwire, Pathcorse (Boston Scientific Co., Marlborough, Massachusetts, United States); Revo wave- $\alpha$ UltraHard 2 (Piolax Medical Devices, Kanagawa, Japan); and M-through (Medico's HIRATAOsaka, Japan) (ฉ Fig.1). Fexibility of the tip, shaft stiffness, and the ability to form a loop were evaluated for each type in an ex vivo model. Characteristics of guidewires used in this study was shown in $>$ Table 1. All guidewires were provided with research funding from Osaka Medical College.

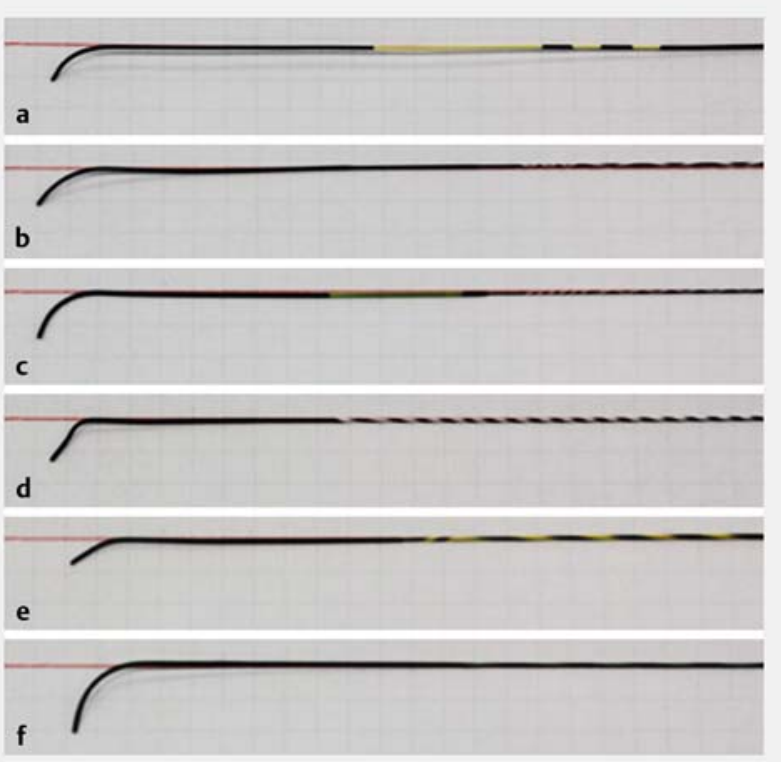

- Fig. 1 Images of guidewires in this study. a MICHISUJI (KANEKA Medical, Osaka, Japan). b M-through (Medico's HIRATAOsaka, Japan). c VisiGlide 2 (Olympus Medical Systems, Tokyo, Japan. d Revo wave- $\alpha$ UltraHard 2 (Piolax Medical Devices, Kanagawa, Japan). e Jagwire (Boston Scientific Co., Marlborough, Massachusetts, United States). f Pathcorse (Boston Scientific Co., Marlborough, Massachusetts, United States).

\section{Measurement of tip flexibility and shaft stiffness}

- Fig. 2 a shows measurements of flexibility for the guidewire tip. The shaft of each guidewire was pinched with an iron block. The guidewire was then pushed at a distance of $3 \mathrm{~mm}$ from the tip using a load-testing device (EZ-TEST; Shimadzu Corp., Kyoto, Japan). Pushing speed was $5 \mathrm{~mm} / \mathrm{min}$ with a $5-\mathrm{N}$ force. Denting of the guidewire itself until deformation of $0.5 \mathrm{~mm}$ was performed using the same load-testing device. The same test was performed at sites $5,10,15,20,25$, and $30 \mathrm{~mm}$ from the tip. We measured these values in newtons (N). During ERCP, the guidewire was first inserted into the biliary or pancreatic duct until it was $30 \mathrm{~mm}$ from the tip. Given the length of the branch of the pancreatic or intrahepatic bile duct, we considered this

- Table 1 Characteristics of guidewires used in this study.

\begin{tabular}{|l|l|l|l|l|l|l|}
\hline Brand name & Manufacturer & $\begin{array}{l}\text { Length of soft } \\
\text { tips } \mathbf{( m m})\end{array}$ & Sheath material & $\begin{array}{l}\text { Tip core } \\
\text { material }\end{array}$ & $\begin{array}{l}\text { Spiral coiled } \\
\text { spring }\end{array}$ \\
\hline MICHISUJI & KANEKA & 50 & PTFE & Ti-Ni & No & Hydrophilic coating \\
\hline VisiGlide 2 & Olympus & 70 & PTFE & Nitinol & No & Hydrophilic coating \\
\hline Pathcorse & Boston & 70 & PTFE & Ti-Ni & Yes & Hydrophilic coating \\
\hline RevoWave & Piolax & 50 & PTFE & Ti-Ni & Yes & Hydrophilic coating \\
\hline M-through & Medico's HIRATA & 75 & PTFE & Ti-Ni & No & Hydrophilic coating \\
\hline Jagwire & Boston & 50 & PTFE & Tungsten & No & Hydrophilic coating \\
\hline
\end{tabular}

Ti-Ni, titanium and nickel alloy; PTFE, polytetrafluoroethylene 


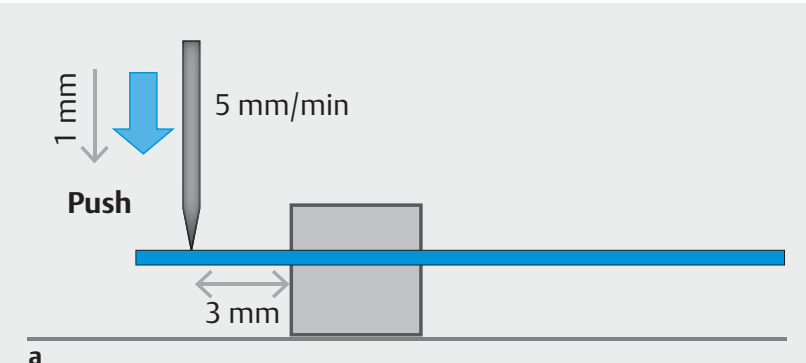

a

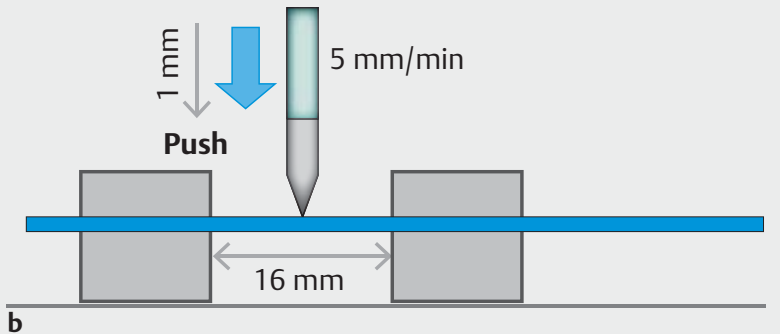

- Fig. 2 Measurement of a flexibility and $\mathbf{b}$ stiffness at the guidewire tip. a The shaft of each guidewire is pinched between iron blocks. The guidewire is pushed at a distance of $3 \mathrm{~mm}$ from the tip using a load-testing device (EZ-TEST, Shimadzu Corp., Kyoto, Japan). Pushing speed is $5 \mathrm{~mm} / \mathrm{min}$ with a $5-\mathrm{N}$ force. Denting of the guidewire itself to a deformation of $0.5 \mathrm{~mm}$ is performed using a load-testing device. The same operation is attempted at 5-, 10-, 15-, 20-, 25-, and 30-cm sites. b The guidewire is pinched between iron blocks (width, $16 \mathrm{~mm}$ ). The guidewire is then pushed at the center between two iron blocks using a load-testing device. Pushing speed is also $5 \mathrm{~mm} / \mathrm{min}$ with a $5-\mathrm{N}$ force. This measurement is performed at distances from $40 \mathrm{~mm}$ to $120 \mathrm{~mm}$ from the tip.

point on the guidewire a useful reflection of guidewire flexibility.

- Fig. 2b shows measurements of shaft stiffness for each guidewire. A guidewire was pinched by two iron blocks. The width of each iron block was $16 \mathrm{~mm}$. The guidewire was then pushed to the center between two iron blocks using a loadtesting device. Pushing speed was also $5 \mathrm{~mm} / \mathrm{min}$ with a $5-\mathrm{N}$ force. This measurement was performed at distances from 40 $\mathrm{mm}$ to $120 \mathrm{~mm}$. Stiffness was measured at nine points in the region, from $40 \mathrm{~mm}$ to $120 \mathrm{~mm}$. These sites may be in the bile duct and pancreatic duct after deep cannulation during ERCP, and were thus considered to reflect push ability.

Finally, in these experimental procedures, four units of each type of guidewire were tested, with each unit tested twice.

\section{Ex vivo experimental evaluation of loop shaping}

- Fig. 3 shows an image of guidewire insertion using the loop shape technique. When the guidewire was a loop shape, pancreatic or biliary duct penetration might have been difficult. In addition, - Fig. 4 shows evaluation of the ability to achieve a loop shape in an ex vivo model. The guidewire was inserted into a test tube (length, $70 \mathrm{~mm}$; width, $13.5 \mathrm{~mm}$ ) filled with normal saline. The length of inserted guidewire was $110 \mathrm{~mm}$. Pushing speed was $5 \mathrm{~mm} / \mathrm{s}$, and the procedure was performed until the guidewire was moved $50 \mathrm{~mm}$. During this procedure,
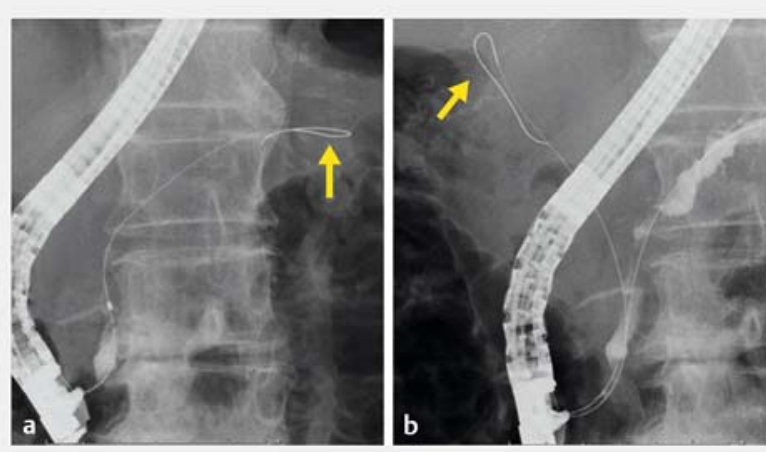

- Fig. 3 Image of loop-shaped guidewire insertion in vivo (a pancreatic duct; $\mathbf{b}$ bile duct). Arrow shows loop shape.
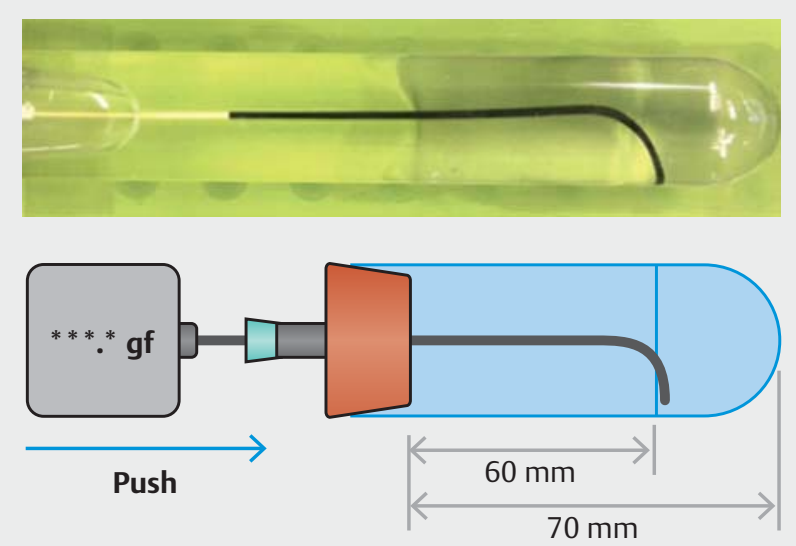

- Fig. 4 Image of loop-shaped guidewire insertion in the ex vivo model. The guidewire is inserted into a test tube (length, $70 \mathrm{~mm}$; width, $13.5 \mathrm{~mm}$ ) filled with normal saline. Length of the inserted guidewire is $110 \mathrm{~mm}$. Pushing speed is $5 \mathrm{~mm} / \mathrm{s}$, and the procedure is performed until the guidewire has been moved $50 \mathrm{~mm}$.

the force required to push the guidewire was consecutively measured using a load testing device (FGPX series; NIDECSHIMPO Corp., Kyoto, Japan). Deformation behavior was also recorded on video, and factors suitable for making a loop shape in each guidewire were evaluated. These experimental procedures were tested twice for each guidewire.

\section{Statistical analysis}

Descriptive statistics are presented as mean \pm standard deviation. Data for tip flexibility and shaft stiffness between guidewires were compared using analysis of variance. Differences showing values of $P<0.05$ were considered statistically significant. All data were statistically analyzed using SPSS version 13.0 statistical software (SPSS Inc., Chicago, Illinois, United States). 


\section{Results}

- Table 2 shows data on tip flexibility for each guidewire. The flexibility of each guidewire differed significantly between each site. Among these, the Revowave and M-through were extremely flexible at $5 \mathrm{~mm}$ from the tip compared with the other four guidewires. On the other hand, the Pathcorse was the stiffest at this site. However, at $10 \mathrm{~mm}$ from the tip, the Revowave was markedly stiffer than the other guidewires.

- Table 3 shows stiffness data for each guidewire. All guidewires showed stepwise increases in stiffness from $40 \mathrm{~mm}$ to $120 \mathrm{~mm}$. However, stiffness of each guidewire differed significantly at each site. At sites $40 \mathrm{~mm}$ and $50 \mathrm{~mm}$ from the tip, Pathcorse was stiffer than other guidewires. At sites $60 \mathrm{~mm}$ to $80 \mathrm{~mm}$ from the tip, Revowave was stiffest. However, at sites $100 \mathrm{~mm}$ and $120 \mathrm{~mm}$ from the tip, Jagwire was the stiffest of the 6 guidewires.

- Fig. 5 shows deformation behaviors of each guidewire. The MICHISUJI achieved a loop shape after the tip contacted the bottom of the test tube ( $>$ Fig. $\mathbf{5 a}$ and $\triangleright$ Video $\mathbf{1}$ ). After moving the guidewire slowly to straighten the wire, the tip was advanced along the curve of the bottom of the test tube. Finally, a loop shape was formed. The M-Through formed a loop shape similar to that of the MICHISUJI after the guidewire tip contacted the bottom of the test tube ( $\boldsymbol{F}$ Fig. $\mathbf{5 b}$ and $\nabla$ Video $\mathbf{2}$ ). The tip of the guidewire then jumped and formed a loop shape. The
VisiGlide 2 also formed a loop shape, similar to the MICHISUJI, then formed a loop ( $\triangleright$ Fig. $5 c$ and $\triangleright$ Video 3 ). After the guidewire was advanced in a loop shape, the tip jumped. Finally, the tip formed a loop shape. The Revowave formed a loop shape in the same way as the MICHISUJI. When the guidewire was inserted further, the tip of the guidewire flipped just before forming a loop, and a loop shape was formed at the guidewire tip ( $>$ Fig. 5d and $\triangleright$ Video 4 ). The Pathcorse ( $\vee$ Fig.5e and $\triangleright$ Video 5 ) and Jagwire ( $\triangleright$ Fig. $\mathbf{5 f}$ and $\triangleright$ Video 6 ) were transformed until a loop similar to the VisiGlide2 was formed. However, the tip of the guidewire could not be made into a loop shape. As shown in - Fig. 6, load was measured while pushing each guidewire. During this experiment, maximum load was lowest for MICHISUJI $(6.8 \mathrm{~g})$, compared with other guidewires [the Jagwire $(11.3 \mathrm{~g})$, M-through (12.9g), VisiGlide 2 (12.9g), Revowave $(21 \mathrm{~g})$, and Pathcorse (25.4g)]. Mean time required to achieve a loop shape was as follows: MICHISUJI, $6.2 \mathrm{~s}$; M-through, $8.7 \mathrm{~s}$; VisiGlide 2, $11.0 \mathrm{~s}$; and Revowave, $7.1 \mathrm{~s}$.

\section{Discussion}

Clinically, guidewires play two important main roles: functioning as guides for placing stents or other devices and providing access to the pancreatic duct or biliary tract. Technical success for these purposes requires different mechanical and functional characteristics. For stent deployment or insertion of various de-

- Table 2 Tip flexibility of each guidewire.

\begin{tabular}{|c|c|c|c|c|c|c|c|c|}
\hline & \multirow[t]{2}{*}{ Sample } & \multirow[t]{2}{*}{ Number } & \multicolumn{6}{|c|}{ Distance from tip / mm } \\
\hline & & & 5 & 10 & 15 & 20 & 25 & 30 \\
\hline \multirow[t]{9}{*}{ MICHISUJI } & A & 1 & 0.052 & 0.065 & & 0.074 & & 0.073 \\
\hline & \multirow[t]{2}{*}{ B } & 1 & 0.045 & 0.052 & 0.058 & 0.057 & 0.056 & 0.065 \\
\hline & & 2 & 0.046 & 0.053 & 0.062 & 0.057 & 0.060 & 0.065 \\
\hline & \multirow[t]{2}{*}{ C } & 1 & 0.040 & 0.049 & 0.059 & 0.063 & 0.065 & 0.067 \\
\hline & & 2 & 0.043 & 0.049 & 0.059 & 0.063 & 0.066 & 0.066 \\
\hline & \multirow[t]{2}{*}{ D } & 1 & 0.045 & 0.055 & 0.065 & 0.066 & 0.061 & 0.062 \\
\hline & & 2 & 0.041 & 0.055 & 0.064 & 0.066 & 0.061 & 0.062 \\
\hline & \multicolumn{2}{|l|}{ Average } & 0.043 & 0.052 & 0.061 & 0.062 & 0.062 & 0.065 \\
\hline & \multicolumn{2}{|l|}{ SD } & 0.002 & 0.003 & 0.003 & 0.004 & 0.003 & 0.002 \\
\hline \multirow[t]{9}{*}{ VisiGlide 2} & A & 1 & 0.083 & 0.103 & & 0.098 & & 0.108 \\
\hline & \multirow[t]{2}{*}{ B } & 1 & 0.054 & 0.066 & 0.092 & 0.096 & 0.098 & 0.094 \\
\hline & & 2 & 0.058 & 0.071 & 0.094 & 0.096 & 0.101 & 0.099 \\
\hline & \multirow[t]{2}{*}{ C } & 1 & 0.099 & 0.091 & 0.088 & 0.095 & 0.109 & 0.151 \\
\hline & & 2 & 0.090 & 0.092 & 0.090 & 0.097 & 0.108 & 0.148 \\
\hline & \multirow[t]{2}{*}{ D } & 1 & 0.106 & 0.085 & 0.086 & 0.088 & 0.111 & 0.136 \\
\hline & & 2 & 0.109 & 0.088 & 0.090 & 0.093 & 0.112 & 0.141 \\
\hline & \multicolumn{2}{|l|}{ Average } & 0.086 & 0.082 & 0.090 & 0.094 & 0.106 & 0.128 \\
\hline & \multicolumn{2}{|l|}{ SD } & 0.024 & 0.011 & 0.003 & 0.003 & 0.006 & 0.025 \\
\hline
\end{tabular}


Table 2 (Continuation)

\begin{tabular}{|c|c|c|c|c|c|c|c|c|}
\hline & \multirow[t]{2}{*}{ Sample } & \multirow[t]{2}{*}{ Number } & \multicolumn{6}{|c|}{ Distance from tip / mm } \\
\hline & & & 5 & 10 & 15 & 20 & 25 & 30 \\
\hline \multirow[t]{9}{*}{ Pathcorse } & A & 1 & 0.116 & 0.150 & & 0.179 & & 0.178 \\
\hline & \multirow[t]{2}{*}{ B } & 1 & 0.123 & 0.136 & 0.133 & 0.133 & 0.161 & 0.152 \\
\hline & & 2 & 0.124 & 0.136 & 0.135 & 0.135 & 0.163 & 0.153 \\
\hline & \multirow[t]{2}{*}{ C } & 1 & 0.074 & 0.098 & 0.103 & 0.129 & 0.146 & 0.162 \\
\hline & & 2 & 0.074 & 0.097 & 0.103 & 0.130 & 0.148 & 0.162 \\
\hline & \multirow[t]{2}{*}{ D } & 1 & 0.078 & 0.081 & 0.115 & 0.146 & 0.176 & 0.186 \\
\hline & & 2 & 0.081 & 0.082 & 0.117 & 0.145 & 0.178 & 0.186 \\
\hline & \multicolumn{2}{|l|}{ Average } & 0.092 & 0.105 & 0.118 & 0.136 & 0.162 & 0.167 \\
\hline & \multicolumn{2}{|l|}{ SD } & 0.024 & 0.025 & 0.014 & 0.007 & 0.014 & 0.016 \\
\hline \multirow[t]{9}{*}{ RevoWave } & A & 1 & 0.017 & 0.127 & & 0.133 & & 0.166 \\
\hline & \multirow[t]{2}{*}{ B } & 1 & 0.018 & 0.059 & 0.088 & 0.088 & 0.128 & 0.161 \\
\hline & & 2 & 0.017 & 0.059 & 0.088 & 0.088 & 0.127 & 0.161 \\
\hline & \multirow[t]{2}{*}{ C } & 1 & 0.021 & 0.097 & 0.103 & 0.099 & 0.148 & 0.184 \\
\hline & & 2 & 0.021 & 0.097 & 0.103 & 0.099 & 0.147 & 0.183 \\
\hline & \multirow[t]{2}{*}{$\mathrm{D}$} & 1 & 0.013 & 0.074 & 0.100 & 0.108 & 0.134 & 0.179 \\
\hline & & 2 & 0.014 & 0.073 & 0.099 & 0.107 & 0.134 & 0.177 \\
\hline & \multicolumn{2}{|l|}{ Average } & 0.017 & 0.076 & 0.097 & 0.098 & 0.136 & 0.174 \\
\hline & \multicolumn{2}{|l|}{ SD } & 0.003 & 0.017 & 0.007 & 0.009 & 0.009 & 0.011 \\
\hline \multirow[t]{9}{*}{ M-through } & A & 1 & 0.018 & 0.032 & & 0.037 & & 0.045 \\
\hline & \multirow[t]{2}{*}{ B } & 1 & 0.020 & 0.035 & 0.047 & 0.045 & 0.047 & 0.053 \\
\hline & & 2 & 0.023 & 0.037 & 0.045 & 0.047 & 0.052 & 0.057 \\
\hline & \multirow[t]{2}{*}{ C } & 1 & 0.020 & 0.037 & 0.038 & 0.037 & 0.049 & 0.055 \\
\hline & & 2 & 0.022 & 0.036 & 0.039 & 0.039 & 0.049 & 0.055 \\
\hline & \multirow[t]{2}{*}{$\mathrm{D}$} & 1 & 0.025 & 0.023 & 0.024 & 0.028 & 0.037 & 0.045 \\
\hline & & 2 & 0.026 & 0.023 & 0.024 & 0.028 & 0.041 & 0.050 \\
\hline & \multicolumn{2}{|l|}{ Average } & 0.023 & 0.032 & 0.036 & 0.037 & 0.046 & 0.052 \\
\hline & \multicolumn{2}{|l|}{ SD } & 0.003 & 0.007 & 0.010 & 0.008 & 0.006 & 0.005 \\
\hline \multirow[t]{11}{*}{ Jagwire } & A & 1 & & & & & & \\
\hline & \multirow[t]{2}{*}{ B } & 1 & 0.054 & 0.064 & 0.069 & 0.070 & 0.069 & 0.071 \\
\hline & & 2 & 0.055 & 0.066 & 0.069 & 0.070 & 0.071 & 0.072 \\
\hline & \multirow[t]{2}{*}{ C } & 1 & 0.057 & 0.077 & 0.073 & 0.074 & 0.076 & 0.077 \\
\hline & & 2 & 0.060 & 0.077 & 0.074 & 0.074 & 0.076 & 0.077 \\
\hline & \multirow[t]{2}{*}{$\mathrm{D}$} & 1 & 0.071 & 0.070 & 0.074 & 0.068 & 0.072 & 0.075 \\
\hline & & 2 & 0.073 & 0.070 & 0.073 & 0.068 & 0.073 & 0.075 \\
\hline & $E$ & 1 & 0.078 & 0.071 & 0.080 & 0.081 & 0.083 & 0.090 \\
\hline & & 2 & 0.079 & 0.071 & 0.080 & 0.081 & 0.083 & 0.090 \\
\hline & Average & & 0.066 & 0.071 & 0.074 & 0.073 & 0.075 & 0.078 \\
\hline & SD & & 0.011 & 0.004 & 0.004 & 0.005 & 0.005 & 0.007 \\
\hline
\end{tabular}


- Table 3 Shaft stiffness of each guidewire.

\begin{tabular}{|c|c|c|c|c|c|c|c|c|c|c|c|}
\hline & \multirow[t]{2}{*}{ Sample } & \multirow[t]{2}{*}{ Number } & \multicolumn{9}{|c|}{ Distance from tip/mm } \\
\hline & & & 40 & 50 & 60 & 70 & 80 & 90 & 100 & 110 & 120 \\
\hline \multirow{9}{*}{ MICHISUJI } & A & 1 & 0.1186 & 0.1497 & 0.2928 & 0.4782 & 0.5215 & 0.8511 & 1.1479 & 1.4707 & 2.0294 \\
\hline & \multirow[t]{2}{*}{ B } & 1 & 0.0954 & 0.1285 & 0.1612 & 0.2995 & 0.4651 & 0.8148 & 1.2270 & 1.7022 & 2.0876 \\
\hline & & 2 & 0.0978 & 0.1297 & 0.1606 & 0.3033 & 0.4765 & 0.8186 & 1.2257 & 1.7210 & 2.0889 \\
\hline & \multirow[t]{2}{*}{ C } & 1 & 0.0899 & 0.1203 & 0.2040 & 0.2468 & 0.4066 & 0.8013 & 1.1788 & 1.4961 & 1.9752 \\
\hline & & 2 & 0.0897 & 0.1219 & 0.2051 & 0.2509 & 0.4063 & 0.8039 & 1.1767 & 1.4927 & 1.9784 \\
\hline & \multirow[t]{2}{*}{$\mathrm{D}$} & 1 & 0.0854 & 0.1267 & 0.1728 & 0.2830 & 0.6058 & 0.8857 & 1.2017 & 1.6091 & 2.1554 \\
\hline & & 2 & 0.0871 & 0.1270 & 0.1800 & 0.2844 & 0.6139 & 0.8855 & 1.1994 & 1.6068 & 2.1593 \\
\hline & \multicolumn{2}{|l|}{ Average } & 0.0909 & 0.1256 & 0.1806 & 0.2780 & 0.4957 & 0.8350 & 1.2015 & 1.6046 & 2.0741 \\
\hline & \multicolumn{2}{|l|}{ SD } & 0.005 & 0.004 & 0.020 & 0.024 & 0.093 & 0.040 & 0.022 & 0.097 & 0.082 \\
\hline \multirow[t]{9}{*}{ VisiGlide 2} & A & 1 & 0.1133 & 0.1212 & 0.2059 & 0.2189 & 0.4073 & 0.4905 & 0.6261 & 1.0493 & 1.5354 \\
\hline & \multirow[t]{2}{*}{ B } & 1 & 0.1053 & 0.1250 & 0.1852 & 0.2575 & 0.3661 & 0.4082 & 0.7240 & 1.1593 & 1.7340 \\
\hline & & 2 & 0.1061 & 0.1260 & 0.1846 & 0.2584 & 0.3635 & 0.4136 & 0.7153 & 1.1593 & 1.7359 \\
\hline & \multirow[t]{2}{*}{ C } & 1 & 0.1053 & 0.1270 & 0.1948 & 0.2154 & 0.3807 & 0.4452 & 0.7501 & 1.2399 & 1.7980 \\
\hline & & 2 & 0.1034 & 0.1264 & 0.1937 & 0.2189 & 0.3815 & 0.4453 & 0.7581 & 1.2415 & 1.7947 \\
\hline & \multirow[t]{2}{*}{ D } & 1 & 0.0974 & 0.1368 & 0.2071 & 0.2637 & 0.3715 & 0.4556 & 0.7589 & 1.1625 & 1.6951 \\
\hline & & 2 & 0.0975 & 0.1366 & 0.2055 & 0.2649 & 0.3689 & 0.4783 & 0.7616 & 1.1632 & 1.7037 \\
\hline & \multicolumn{2}{|l|}{ Average } & 0.1025 & 0.1296 & 0.1951 & 0.2465 & 0.3720 & 0.4410 & 0.7447 & 1.1876 & 1.7436 \\
\hline & \multicolumn{2}{|l|}{ SD } & 0.004 & 0.006 & 0.010 & 0.023 & 0.008 & 0.026 & 0.020 & 0.041 & 0.044 \\
\hline \multirow[t]{9}{*}{ Pathcorse } & A & 1 & 0.1996 & 0.2718 & 0.3645 & 0.4479 & 0.5881 & 0.8177 & 1.1028 & 1.4228 & 1.7702 \\
\hline & \multirow[t]{2}{*}{ B } & 1 & 0.1922 & 0.2604 & 0.3417 & 0.4498 & 0.5800 & 0.8393 & 1.0853 & 1.4135 & 1.7366 \\
\hline & & 2 & 0.1933 & 0.2601 & 0.3416 & 0.4513 & 0.5804 & 0.8399 & 1.0865 & 1.4162 & 1.7336 \\
\hline & \multirow[t]{2}{*}{ C } & 1 & 0.1962 & 0.2633 & 0.3403 & 0.4262 & 0.5583 & 0.7919 & 1.0706 & 1.4814 & 1.8297 \\
\hline & & 2 & 0.1992 & 0.2638 & 0.3418 & 0.4264 & 0.5595 & 0.7920 & 1.0706 & 1.4814 & 1.8265 \\
\hline & \multirow[t]{2}{*}{ D } & 1 & 0.2030 & 0.2865 & 0.3823 & 0.4492 & 0.6103 & 0.8795 & 1.1194 & 1.3675 & 1.7303 \\
\hline & & 2 & 0.2024 & 0.2861 & 0.3839 & 0.4461 & 0.6096 & 0.8768 & 1.1187 & 1.3661 & 1.7291 \\
\hline & \multicolumn{2}{|l|}{ Average } & 0.1977 & 0.2700 & 0.3553 & 0.4415 & 0.5830 & 0.8366 & 1.0918 & 1.4210 & 1.7643 \\
\hline & \multicolumn{2}{|l|}{ SD } & 0.005 & 0.013 & 0.022 & 0.012 & 0.023 & 0.039 & 0.022 & 0.051 & 0.049 \\
\hline \multirow[t]{9}{*}{ RevoWave } & A & 1 & 0.2816 & 0.2219 & 0.3357 & 0.5270 & 0.7460 & 0.9837 & 1.2534 & 1.5973 & 2.0555 \\
\hline & \multirow[t]{2}{*}{ B } & 1 & 0.1672 & 0.2486 & 0.3814 & 0.5229 & 0.7223 & 0.9177 & 1.2246 & 1.6107 & 2.0452 \\
\hline & & 2 & 0.1681 & 0.2485 & 0.3806 & 0.5215 & 0.7234 & 0.9177 & 1.2222 & 1.6116 & 2.0452 \\
\hline & \multirow[t]{2}{*}{ C } & 1 & 0.1748 & 0.2418 & 0.3804 & 0.5183 & 0.6891 & 0.9927 & 1.2448 & 1.6334 & 2.0220 \\
\hline & & 2 & 0.1759 & 0.2418 & 0.3814 & 0.5181 & 0.6923 & 0.9895 & 1.2515 & 1.6275 & 2.0270 \\
\hline & $\mathrm{D}$ & 1 & 0.1732 & 0.2467 & 0.3806 & 0.5063 & 0.6988 & 0.9383 & 1.1986 & 1.5232 & 1.9145 \\
\hline & & 2 & 0.1729 & 0.2474 & 0.3800 & 0.5056 & 0.6989 & 0.9392 & 1.1982 & 1.5257 & 1.9170 \\
\hline & Average & & 0.1720 & 0.2458 & 0.3807 & 0.5154 & 0.7041 & 0.9492 & 1.2233 & 1.5887 & 1.9951 \\
\hline & SD & & 0.004 & 0.003 & 0.001 & 0.008 & 0.015 & 0.034 & 0.022 & 0.051 & 0.062 \\
\hline
\end{tabular}


- Table 3 (Continuation)

\begin{tabular}{|c|c|c|c|c|c|c|c|c|c|c|c|}
\hline & \multirow[t]{2}{*}{ Sample } & \multirow[t]{2}{*}{ Number } & \multicolumn{9}{|c|}{ Distance from tip/mm } \\
\hline & & & 40 & 50 & 60 & 70 & 80 & 90 & 100 & 110 & 120 \\
\hline \multirow[t]{9}{*}{ M-through } & A & 1 & 0.1063 & 0.1693 & 0.2025 & 0.2745 & 0.3908 & 0.4934 & 0.6706 & 0.9872 & 1.3147 \\
\hline & \multirow[t]{2}{*}{ B } & 1 & 0.1285 & 0.2179 & 0.2118 & 0.2653 & 0.4874 & 0.6031 & 0.8363 & 1.1317 & 1.4093 \\
\hline & & 2 & 0.1342 & 0.2114 & 0.2133 & 0.2681 & 0.4932 & 0.6010 & 0.8371 & 1.1408 & 1.4013 \\
\hline & \multirow[t]{2}{*}{ C } & 1 & 0.1075 & 0.1824 & 0.2198 & 0.3405 & 0.4773 & 0.6315 & 0.8684 & 1.1680 & 1.4622 \\
\hline & & 2 & 0.1130 & 0.1909 & 0.2218 & 0.3373 & 0.4748 & 0.6317 & 0.8632 & 1.1701 & 1.4649 \\
\hline & \multirow[t]{2}{*}{ D } & 1 & 0.1011 & 0.1684 & 0.1992 & 0.3134 & 0.4617 & 0.5183 & 0.7689 & 1.1089 & 1.3288 \\
\hline & & 2 & 0.1040 & 0.1744 & 0.2225 & 0.3140 & 0.4652 & 0.5168 & 0.7717 & 1.1070 & 1.3248 \\
\hline & \multicolumn{2}{|l|}{ Average } & 0.1147 & 0.1909 & 0.2148 & 0.3064 & 0.4766 & 0.5837 & 0.8243 & 1.1377 & 1.3985 \\
\hline & \multicolumn{2}{|l|}{ SD } & 0.014 & 0.020 & 0.009 & 0.033 & 0.012 & 0.053 & 0.044 & 0.028 & 0.061 \\
\hline \multirow[t]{8}{*}{ Jagwire } & \multirow[t]{2}{*}{ B } & 1 & 0.0755 & 0.0920 & 0.1900 & 0.3244 & 0.5882 & 0.9244 & 1.3992 & 1.9363 & 2.2688 \\
\hline & & 2 & 0.0751 & 0.0912 & 0.1896 & 0.3245 & 0.5879 & 0.9240 & 1.3981 & 1.9386 & 2.2679 \\
\hline & \multirow[t]{2}{*}{ C } & 1 & 0.0764 & 0.1036 & 0.2027 & 0.3347 & 0.5611 & 0.9247 & 1.4480 & 1.9465 & 2.2483 \\
\hline & & 2 & 0.0765 & 0.1033 & 0.2031 & 0.3351 & 0.5610 & 0.9245 & 1.4479 & 1.9460 & 2.2597 \\
\hline & \multirow[t]{2}{*}{ E } & 1 & 0.0789 & 0.0924 & 0.1869 & 0.3286 & 0.5753 & 0.9426 & 1.3841 & 1.9091 & 2.1966 \\
\hline & & 2 & 0.0794 & 0.0934 & 0.1868 & 0.3307 & 0.5757 & 0.9430 & 1.3884 & 1.9104 & 2.2039 \\
\hline & \multicolumn{2}{|l|}{ Average } & 0.077 & 0.096 & 0.193 & 0.330 & 0.575 & 0.931 & 1.411 & 1.931 & 2.241 \\
\hline & \multicolumn{2}{|l|}{ SD } & 0.002 & 0.006 & 0.008 & 0.005 & 0.012 & 0.010 & 0.029 & 0.017 & 0.032 \\
\hline
\end{tabular}

vices such as an ERCP catheter over the guidewire, stiffness of the shaft is extremely relevant. On the other hand, to provide access to the pancreatic duct or bile duct, tip flexibility promotes easy passage. In addition, this function might also play an important role in preventing pancreatic or bile duct penetration. A combination of these characteristics in a guidewire might thus be beneficial. Novel guidewires with these characteristics have recently been produced, especially with respect to tip flexibility. To prevent duct penetration, a loop-shaped guidewire might be useful, and many endoscopists also consider tip flexibility to play an important role in forming a loop shape. However, according to the present experimental study, flexibility alone was insufficient to form a loop shape. In addition, compared with a previous study [15], our study showed advantages such as measurement of tip bending force using more sensitive instruments.

In the present study of deformation behaviors for each guidewire, the MICHISUJI began to form a loop shape after the guidewire tip curved along the curved bottom of the test tube. When a guidewire up to $20 \mathrm{~mm}$ from the tip came into contact with the curved bottom of the test tube, contact resistance prevented further insertion of the guidewire. The loop shape was then most likely formed when a force in the direction of compression was applied more than $20 \mathrm{~mm}$ from the guidewire tip. This contact resistance might occur due to stiffness at a distance of around $20 \mathrm{~mm}$ from the tip of the guidewire. If the guidewire is stiff around this site, the force to return the wire into a straight shape is strong. The guidewire is thus pushed to the wall surface at the bottom of the test tube as well. In addition, because deformation behaviors after loop shape formation differed among guidewires, stiffness of the guidewire beyond a distance of $30 \mathrm{~mm}$ from the tip might affect the maximum load required to make a loop shape. To evaluate this hypothesis, stiffness of the guidewire was measured 40 to $120 \mathrm{~mm}$ from the tip of the guidewire. As shown in > Table 2, at a distance of $20 \mathrm{~mm}$ from the tip, the MICHISUJ was continuously flexible, and was thus able to be advanced after the tip came into contact with the bottom of the test tube without guidewire jumping. Little load was required before the MICHISUJI formed a loop shape due to the above. On the other hand, the M-Through was most flexible at 20 to $30 \mathrm{~mm}$ from the tip. However, flexibility was gradually decreased from 20 to $30 \mathrm{~mm}$. When the tip came into contact with the bottom of the test tube, deformation therefore occurred at a distance beyond $30 \mathrm{~mm}$. On touching the test tube wall, the maximum load required to form a loop shape most likely exceeded that of the MICHISUJI. The VisiGlide 2 was almost flexible compared with other guidewires at 40 to $120 \mathrm{~mm}$. Maximum load before forming a loop shape was thus higher than for the MICHISUJI, for the same reason as for the M-Through. The guidewire was stiff at more than $40 \mathrm{~mm}$ from the tip of the RevoWave, and was also stiff at a distance of $20 \mathrm{~mm}$. Maximum load to form a loop shape was the highest for this guidewire. On the other hand, at $20 \mathrm{~mm}$ and $30 \mathrm{~mm}$ from the tip, the Pathcorse was one of stiffest of the guidewires. A loop shape thus could not be made. With respect to loop shape, the MICHISUJI might there- 

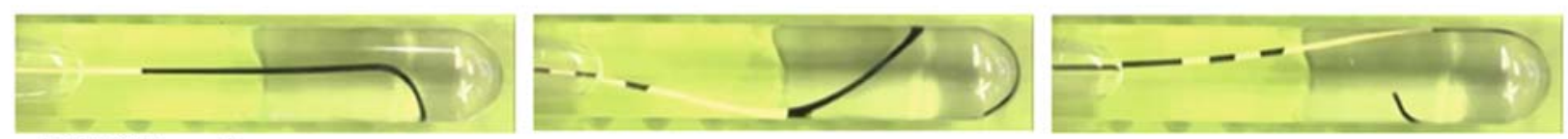

a MICHISUJI, angle
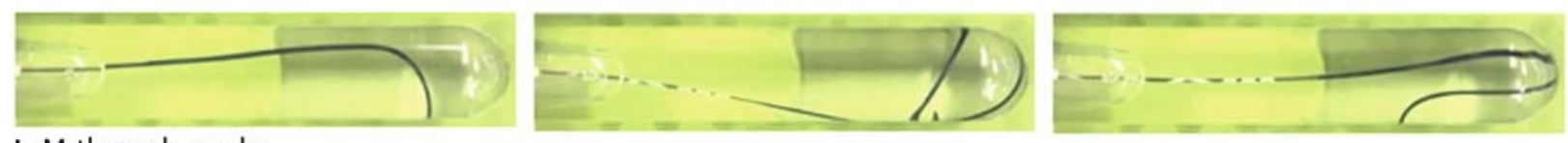

b M-through, angle
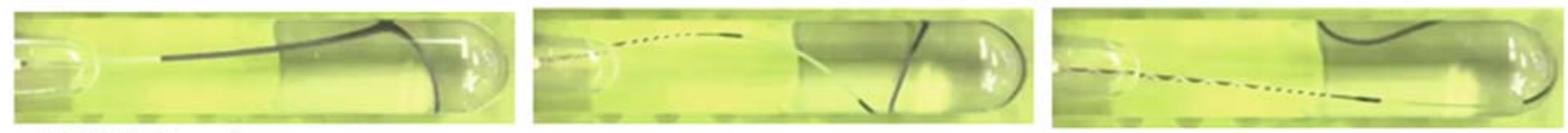

c VisiGlide 2, angle
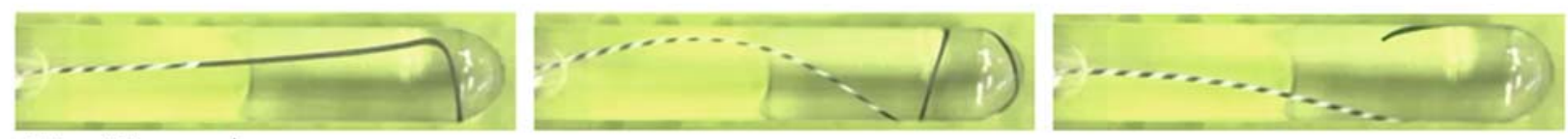

d RevoWave, angle
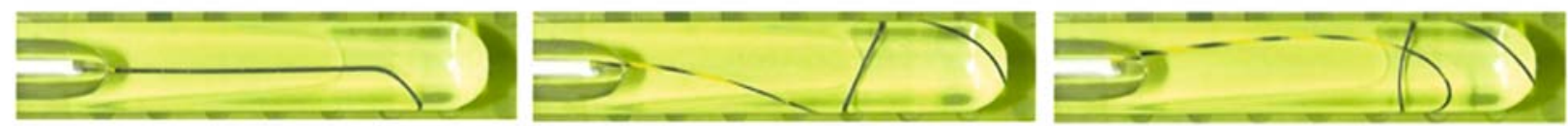

e Jagwire, angle
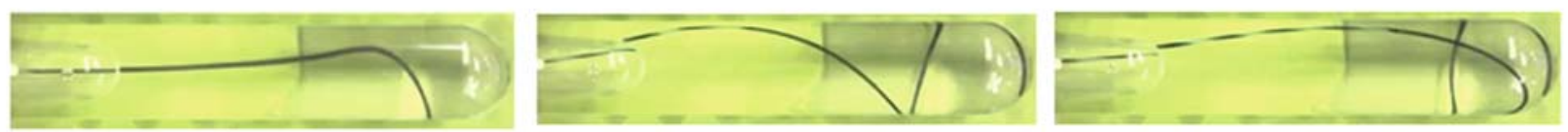

f Pathcoarse, angle

Fig. 5 Deformation behaviors of each guidewire. This experimental procedure is tested twice for each guidewire, and behaviors are the same for each test. The a MICHISUJI, $\mathbf{b}$ M-Through, $\mathbf{c}$ VisiGlide 2, and $\mathbf{d}$ Revowave make a loop shape, whereas the $\mathbf{e}$ Jagwire and $\mathbf{f}$ Pathcorse cannot make a loop shape.

fore be the most suitable. In clinical practice, for patients at risk of post-ERCP pancreatitis, the MICHISUJI may be clinically useful, although confirmation in a clinical trial is needed. However, although the loop shape may help prevent duct penetration $[10,11]$, creation of the loop shape may make guidewire passage through stricture sites more challenging. This function should therefore also be evaluated in an experimental study. However, our study aimed to evaluate loop shape with the aim of preventing $A E s$, and did not investigate penetration ability. Further experimental study is needed.

Limitations of the present study were as follows. First, the environment of this study differed from in vivo conditions. Second, although the aim of the study was to evaluate how guidewires form a loop shape, the role of lubricity in each guidewire was not examined. In addition, the core wire constituting the guidewire, such as monofilament wires or monofilament wires covered with spiral coiled spring, might have influenced stricture penetration during cannulation [16]. Our experimental study did not account for this factor. Further, twisting the element might be an important factor in creating a loop shape. This issue was also not evaluated in the present study. Third, during evaluation of the deformation behaviors of each guidewire, the test tube was filled with normal saline. In vivo, the guidewire would be maneuvered within bile or pancreatic juice. Finally, many kinds of guidewires are available around the world, but only six guidewires were evaluated in the present study, even though these guidewires are frequently used in Japan.

\section{Conclusion}

In conclusion, characteristics of flexibility and stiffness among guidewires differed significantly in an ex-vivo study. In this experimental study regarding deformation behavior until a loop shape was formed, maximum loads also differed. To evaluate whether guidewires easily form a loop shape, clinical study is needed. 


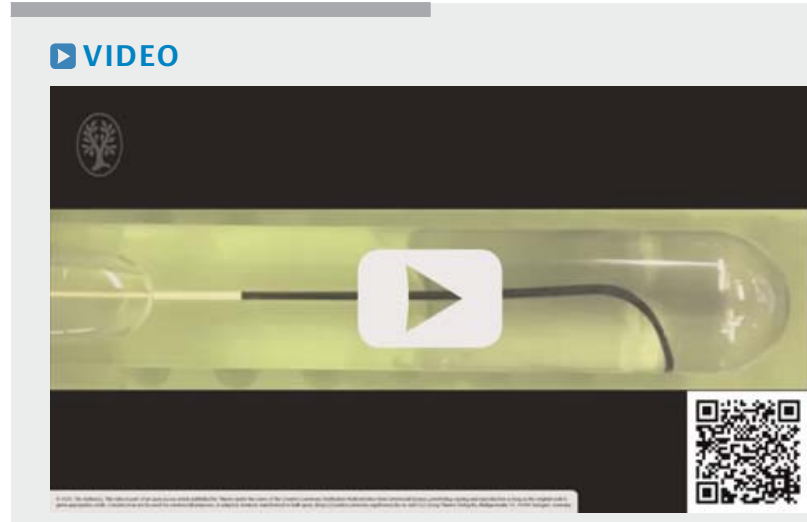

- Video 1 Deformation behavior of each guidewire. This experimental procedure is tested twice for each guidewire, and behaviors are the same for each test. The MICHISUJI

\section{$\triangle$ VIDEO}

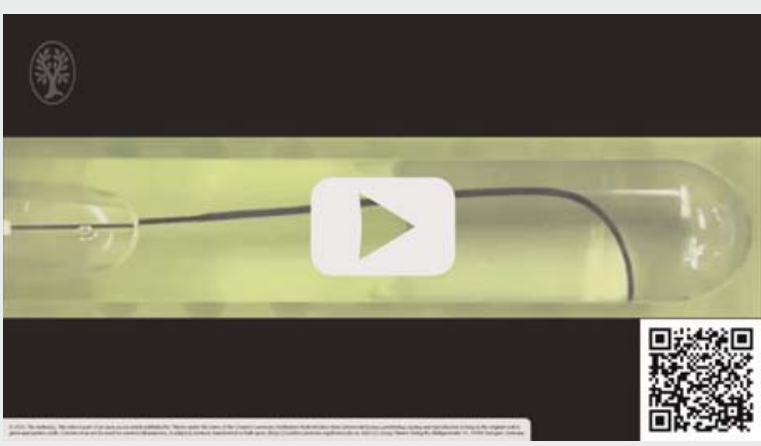

- Video 2 Deformation behavior of each guidewire. This experimental procedure is tested twice for each guidewire, and behaviors are the same for each test. M-through

\section{$\triangle$ VIDEO}

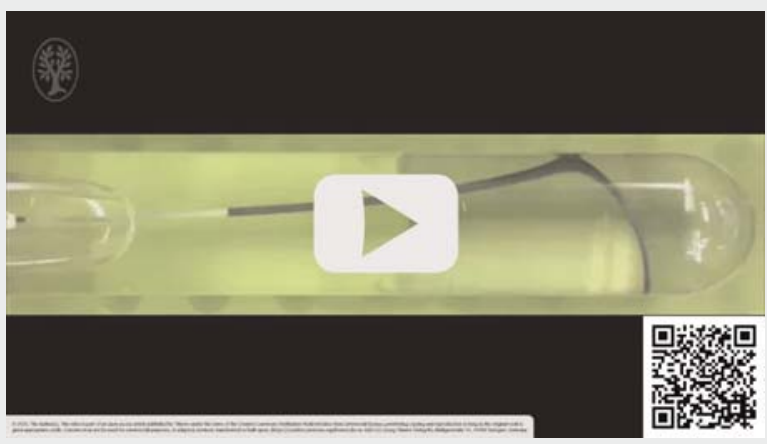

- Video 3 Deformation behavior of each guidewire. This experimental procedure is tested twice for each guidewire, and behaviors are the same for each test. VisiGlide 2

\section{VIDEO}

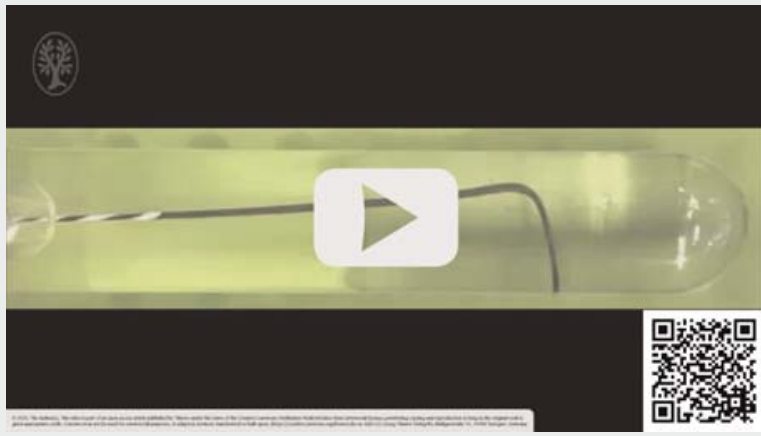

- Video 4 Deformation behavior of each guidewire. This experimental procedure is tested twice for each guidewire, and behaviors are the same for each test. Revowave make loop shapes

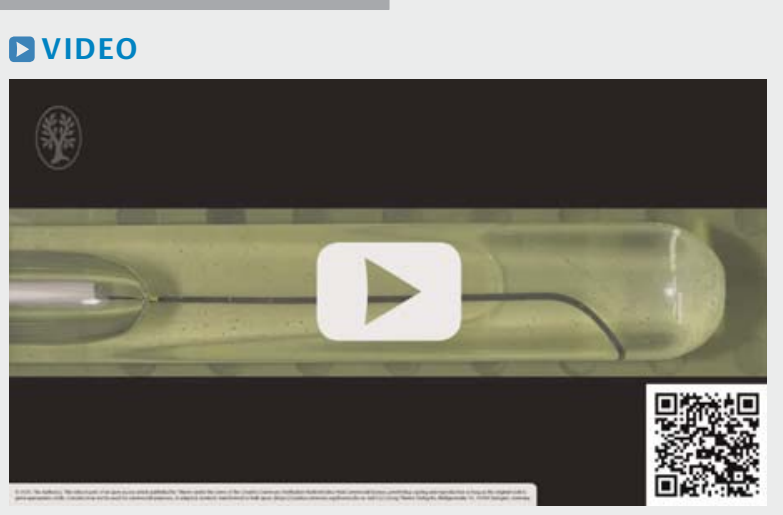

- Video 5 Deformation behavior of each guidewire. This experimental procedure is tested twice for each guidewire, and behaviors are the same for each test. The Jagwire

\section{DIDEO}

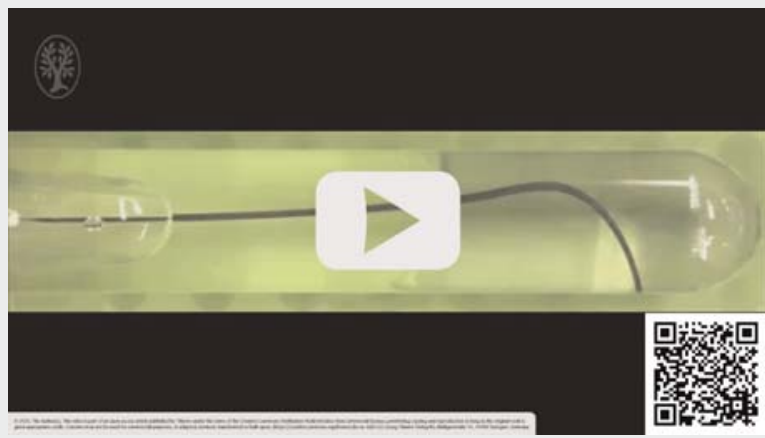

Video 6 Deformation behavior of each guidewire. This experimental procedure is tested twice for each guidewire, and behaviors are the same for each test. Pathcorse fail to make a loop shape 

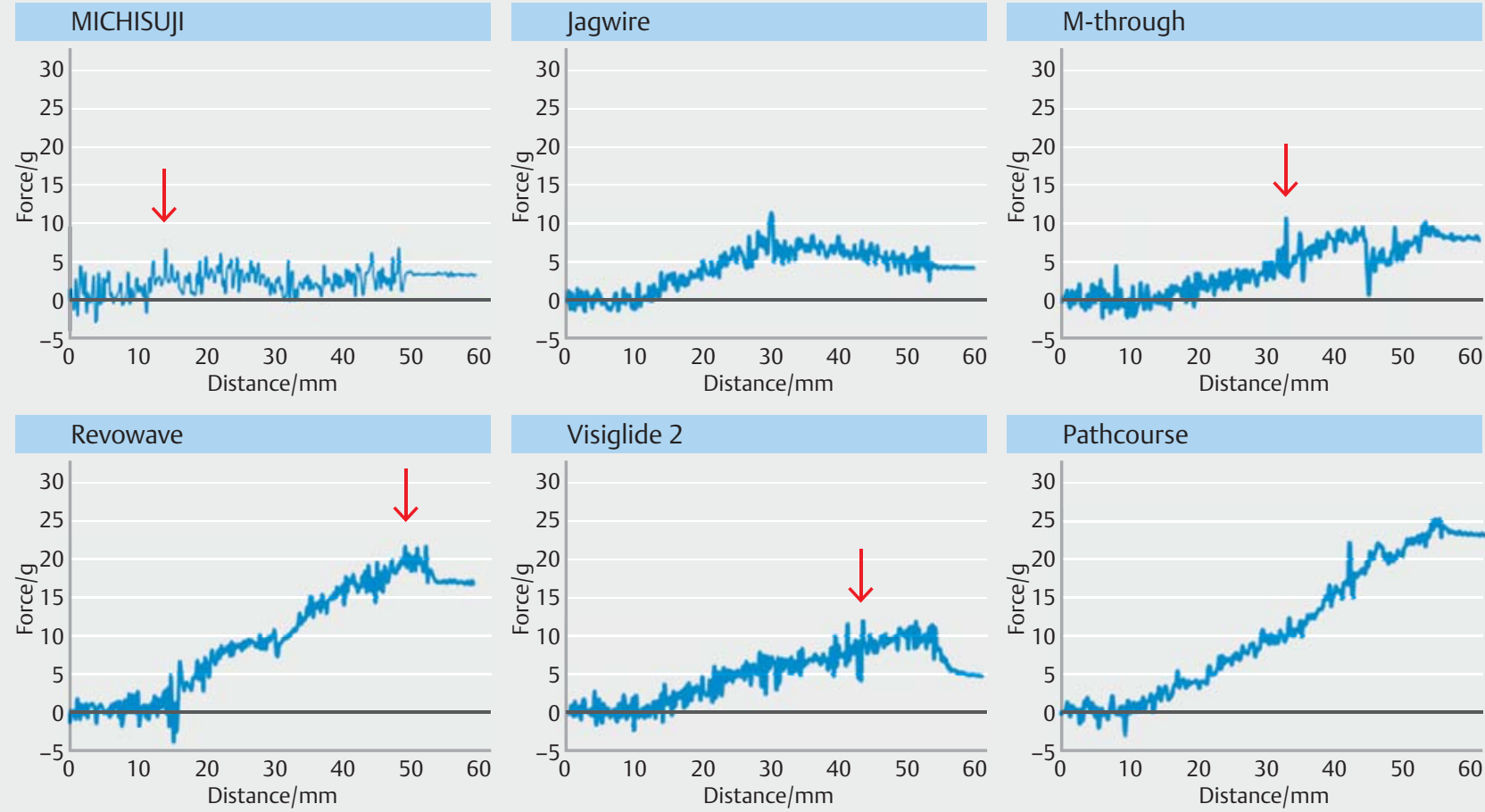

Visiglide 2

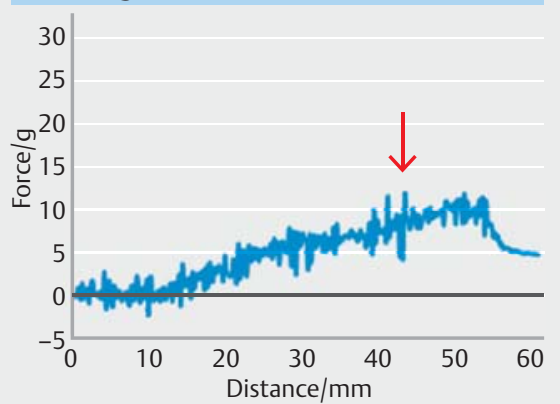

Pathcourse

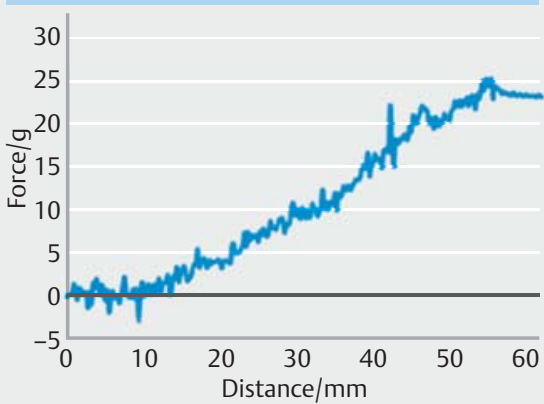

- Fig. 6 Load measurements while pushing each guidewire. During this experiment, maximum load was lowest for a MICHISUJI (6.8 g), followed by $\mathbf{b}$ the Jagwire (11.3 g), $\mathbf{c}$ M-through ( $12.9 \mathrm{~g})$, d VisiGlide 2 (12.9 g), e Revowave ( $21 \mathrm{~g})$, and $\mathbf{f}$ Pathcorse $(25.4 \mathrm{~g})$. Arrow shows the distance at which the guidewire forms a loop shape.

\section{Acknowledgments}

The authors extend our special thanks to Youhei Kurose, Akihiko Takei, Daisuke Shimizu, Haruka Kamogawa and all members of KANEKA for providing valuable information on conducting these experimental studies and lending us the experimental devices.

\section{Competing interests}

Dr. Ogura is a consultant for KANEKA.

\section{References}

[1] Tse F, Yuan Y, Moayyedi P et al. Double-guidewire technique in difficult biliary cannulation for the prevention of post-ERCP pancreatitis: a systematic review and meta-analysis. Endoscopy 2017; 49: 15-26

[2] Coté GA, Ansstas M, Pawa R et al. Difficult biliary cannulation: use of physician-controlled wire-guided cannulation over a pancreatic duct stent to reduce of precut sphincterotomy (with video). Gastrointest Endosc 2010; 71: 275-279

[3] Isayama H, Komatsu Y, Tsujino T et al. A prospective randomized study of "covered" versus "uncovered" diamond stents for the management of distal malignant biliary obstruction. Gut 2004; 53: 729734
[4] Ogura T, Takenaka M, Shiomi $\mathrm{H}$ et al. Single-session multiple stent deployment using moving cell stent without initial stent mesh to treat malignant hilar biliary obstruction (with videos). J Hepatobiliary Pancreat Sci 2020; 27: 84-89

[5] Itoi T, Sofuni A, Itokawa F et al. Current status and issues regarding biliary stenting in unresectable biliary obstruction. Dig Dis Sci 2013; 25: $63-70$

[6] Ogura T, Yamada M, Ueno S et al. Hybrid placement technique for hepatic hilar obstruction using a new uncovered self-expandable metal stent. Endosc Int Open 2019; 7: E1288-E1292

[7] Teoh AYB, Dhir V, Kida M et al. Consensus guideline on the optimal management in interventional EUS procedures: results from the Asian EUS group RAND/UCLA expert panel. Gut 2018; 67: 1209-1228

[8] Dhir V, Isayama H, Itoi T et al. Endoscopic ultrasonography-guided biliary and pancreatic duct interventions. Dig Endosc 2017; 29: 472485

[9] Ogura T, Yamada M, Nishioka N et al. Gastrointestinal: Knuckle guidewire insertion: Safe techniques of guidewire insertion into the pancreatobiliary tract using a novel 0.025 -inchu guidewire. J Gastroenterol Hepatol 2020; 35: 707

[10] Masci E, Mangiavillano B, Luigiano C et al. Comparison between looptip guidewire assisted and conventional endoscopic cannulation in high risk patients. Endosc Int Open 2015; 3: E464-E470

[11] Saki Y, Tsuyuguchi T, Sugiyama H et al. Prevention of post-endoscopic retrograde cholangiopancreatography pancreatitis by pancreatic duct stenting using a loop-tipped guidewire. World J Clin Cases 2016; 16: $213-218$

[12] Takashima K, Tsuzuki S, Ooike A et al. Numerical analysis and experimental observation of guidewire motion in a blood vessel model. Med Eng Phys 2014; 36: 1672-1683 
[13] Bagbanci S. Holmium: Yttrium aluminum garnet laser and guidewires: is there a durability difference among guidewires against laser energy? An In Vitro Experimental Study. J Endourol 2017; 31: 528532

[14] Kwiatkowski PS, Malachowski J, Jakubas-Kwiatkowska W et al. The effects of types of guidewires and pressure applied during stent implantation in the main vessel on the incidence of damage to coronary guidewires during angioplasty of coronary bifurcation lesions-Wide Beast study. J Interv Cardiol 2018; 31: 599-607

[15] Kwon Cl, Koh DH, Song T] et al. Technical reports of ERCP guidewire on the basis of physical properties. Clin Endosc 2020; 53: 65-72

[16] Park JS, Jeong S, Lee DH. Effectiveness of a novel highly flexible-tip guidewire on selective biliary cannulation compared to conventional guidewire: randomized controlled study. Dig Endosc 2018; 30: 245251 